\title{
Advances in the treatment of gastroenteropancreatic neuroendocrine tumors
}

This article was published in the following Dove Press journal:

Clinical and Experimental Gastroenterology

25 June 2010

Number of times this article has been viewed

\section{Pamela L Kunz \\ George A Fisher}

Stanford University Medical Center, CA, USA
Correspondence: George Fisher Stanford University Medical Center, 875 Blake Wilbur Drive, Stanford,

CA 94305, USA

$\mathrm{Tel}+\mathrm{I}$ 650-725-9057

Fax +l 650-498-5353

Email georgeaf@stanford.edu.

\begin{abstract}
Gastroenteropancreatic neuroendocrine tumors (GEP-NETs) are a rare and heterogeneous class of neoplasms. While surgical resection is the mainstay of treatment, non-surgical therapies play a role in the setting of unresectable and metastatic disease. The goals of medical therapy are directed both at alleviating symptoms of peptide release and shrinking tumor mass. Biotherapies such as somatostatin analogs and interferon can decrease the secretion of peptides and inhibit their end-organ effects. A second objective for treatment of unresectable GEP-NETs is limiting tumor growth. Options for limiting tumor growth include somatostatin analogs, systemic chemotherapy, locoregional therapies, ionizing radiation, external beam radiation, and newer targeted agents. In particular, angiogenesis inhibitors, tyrosine kinase inhibitors, and mTOR inhibitors have shown early promising results. The rarity of these tumors, their resistance to standard chemotherapy, and the excellent performance status of most of these patients, make a strong argument for consideration of novel therapeutic trials.
\end{abstract}

Keywords: neuroendocrine, gastroenteropancreatic, carcinoid, somatostatin

\section{Introduction}

Gastroenteropancreatic neuroendocrine tumors (GEP-NETs) are a rare and heterogeneous class of neoplasms. Common gastrointestinal sites of origin include the endocrine pancreas and argentaffin cells of the gut which give rise to carcinoid tumors. Incidence rates range from 1-5/100,000, and recent reports have suggested an increasing incidence at several sites. ${ }^{1}$ Most GEP-NETs are malignant yet grow slowly in comparison with their adenocarcinoma counterparts. Most are functionally inactive but some produce hormones which lead to the clinical syndromes associated with hormone excess. Neuroendocrine tumors may arise sporadically or be associated with multiple endocrine neoplasia (MEN). Specifically, 10\% of pancreatic neuroendocrine tumors (NETs) are associated with MEN 1, an autosomal dominant predisposition to parathyroid, pituitary, and pancreatic NETs.

Historically, there has been much debate about the nomenclature and classification of GEP-NETs. The inconsistency in classification and nomenclature has been problematic. One common classification of endocrine tumors is according to the embryologic site of origin (ie, foregut, midgut, and hindgut). However, tumors of the foregut, which include the respiratory system, stomach, duodenum, proximal jejunum, and pancreas, are not comparable in terms of behavior and response to therapy. The 1980 World Health Organization (WHO) classification instead subdivided the endocrine gastrointestinal tumors into enterochromaffin $(\mathrm{EC})$ cell, gastrin $(\mathrm{G})$ cell, and unspecified carcinoids. In 2000, the WHO proposed a new classification schema which includes 
clinical, molecular, and histopathological features and suggested that the most appropriate terms to describe such tumors should be "endocrine tumor" or "neuroendocrine tumor". ${ }^{2}$ Specifically, this latest system recognizes the biologic behavior according to location, degree of tumor differentiation, and peptide secreted, thus incorporating many features of prior classification attempts.

The new WHO classification is intended to address the need for a clinically relevant classification system, and we will review the medical treatment of GEP-NETs in this context. While surgical resection is the mainstay of treatment, non-surgical therapies play a role in the setting of unresectable and metastatic disease. The goals of medical therapy are directed both at alleviating symptoms of peptide release and shrinking tumor mass.

\section{Mediating the effects of peptide release}

Most functional tumors of the gastroenteropancreatic system arise in the pancreas and include insulinomas, gastrinomas, VIPomas, glucagonomas, and somatostatinomas. Other functional tumors include duodenal gastrin-producing tumors and carcinoid tumors which generally occur in the ileum or appendix. Hindgut tumors are always nonfunctional. Biotherapies such as somatostatin analogs can both decrease the secretion of such peptides and inhibit their end-organ effects.

\section{Somatostatin analogs}

Somatostatin analogs are the mainstay of symptom management for patients with functional GEP-NETs. Somatostatin is a naturally occurring polypeptide produced by paracrine cells that are scattered throughout the gastrointestinal tract. Somatostatin inhibits gastrointestinal endocrine and exocrine function including the release of insulin, gastrin, glucagon, gastric, and pancreatic secretions. Somatostatin was first used to control symptoms caused by GEP-NETs in the 1970s. ${ }^{3,4}$ Somatostatin has a 2-minute half-life and therefore required a cumbersome continuous infusion and caused rebound hypersecretion of hormones. These characteristics made somatostatin clinically impractical. Since then, longer-acting somatostatin analogs have been developed which have facilitated outpatient use and minimized rebound symptoms.

Octreotide was the first somatostatin analog introduced for clinical use. It has a half-life of 2 hours, requiring 2-3 daily injections, and is not associated with the rebound symptoms that plagued the use of somatostatin.
A meta-analysis of 62 published studies was performed in 1999 and examined the relationship between the shortacting octreotide dose and efficacy in terms of decreasing urinary 5-HIAA levels, flushing, and diarrhea. ${ }^{5}$ The analysis found that increasing doses of octreotide (100-1000 $\mu \mathrm{g} /$ day) were directly associated with decreasing 5-HIAA levels and symptom improvement. Individualized dose titration was emphasized.

A longer-acting octreotide formulation (octreotide acetate LAR [long-acting repeatable]) was developed in the mid 1990s. The slow microsphere drug release of the LAR preparation offers the convenience of monthly intramuscular dosing. Studies comparing the shorter-acting and longeracting forms of octreotide have demonstrated equal efficacy in terms of symptom control, with symptomatic response rates of $60 \%$ to $72 \%$ across groups. ${ }^{6}$ Other studies have reported $65 \%$ to $100 \%$ response rates with octreotide LAR. Initiation of octreotide LAR often requires coverage with a short-acting formulation for 2-3 weeks until steady-state levels of LAR are achieved.

Lanreotide LA and lanreotide Autoge ${ }^{\circledR}$ are more prolonged release formulations of octreotide. Lanreotide LA is a single strength, slow-release microparticle, administered intramuscularly every 14 days. Like octreotide LAR, lanreotide LA usually requires coverage with the shorter-acting octreotide until steady state-levels are reached. The symptomatic response rates with lanreotide LA range from $45 \%$ to $90 \%$. $^{7}$ Studies evaluating lanreotide versus short-acting octreotide in terms of efficacy, patient acceptability, and tolerance have favored lanreotide. ${ }^{8}$ Lanreotide Autogel is a newer formulation supplied as a prefilled syringe of viscous aqueous solution and is administered by deep subcutaneous injection every 28 days and is only available in Europe; studies in the US are ongoing to allow for FDA filing. There are no studies directly comparing the various longer-acting formulations.

The longer-acting somatostatin analogs are generally preferred for chronic symptom management with GEP-NETs because of ease of administration. However, the short-acting octreotide formulation is still preferred prior to invasive procedures for prevention and management of carcinoid crisis.

Somatostatin analogs are well tolerated with only mild side effects. Side effects are generally transient and include nausea, abdominal cramps, flatulence, diarrhea, steatorrhea, hyperglycemia, cholelithiasis, and local injection site reactions. Tachyphylaxis may be seen when somatostatin analogs are used for more than 12 months. 


\section{Interferons}

Interferons (IFNs) have been used alone or in combination with chemotherapy and somatostatin analogs, mainly in the treatment of the carcinoid subset of GEP-NETs. Analysis of pooled data from published studies indicates a median symptomatic response rate of $40 \%$ to $70 \%$ for use of IFN alone, lower than those reported for somatostatin analogs. ${ }^{9}$ Another drawback of IFN therapy when compared with the well tolerated somatostatin analogs is the side effect profile. IFNs are commonly associated with flu-like symptoms, chronic fatigue, depression, thyroid dysfunction, mild hepatotoxicity, and cytopenias. Trials assessing the effectiveness of combination therapy have been mixed in terms of symptomatic response. ${ }^{7,10}$ The primary role for IFN therapy may be in somatostatin-refractory patients.

\section{Decreasing tumor burden}

A second objective of treatment for unresectable GEP-NETs is limiting tumor growth. Although most GEP-NETs are slow growing, primary tumors and metastases can lead to symptoms depending on their anatomic location.

\section{Somatostatin analogs and interferon}

Somatostatin, in addition to its ability to inhibit gastrointestinal endocrine and exocrine function, may have apoptotic and cytostatic effects. Non-randomized trials evaluating response to somatostatin analogs have shown partial responses ranging from $0 \%$ to $38 \%$, and stabilization of disease, ranging from $37 \%$ to $87 \%$, lasting between 8.5 and 18 months. ${ }^{7,11,12}$ The first randomized study of octreotide LAR was recently reported. ${ }^{13}$ In this study (known as PROMID), patients with well-differentiated metastatic midgut neuroendocrine tumors were randomized to intramuscularly administered octreotide LAR $30 \mathrm{mg}$ monthly versus placebo ( $\mathrm{n}=42$ vs 43 ). Median TTP was longer in the treatment arm (14.3 months versus 6 months; HR $0.34, P<0.05$ ) and stable disease was seen in $67 \%$ and $37 \%$ of patients treated with octreotide LAR and placebo, respectively. This trial appears to confirm the antiproliferative potential of somatostatin analogs in midgut carcinoids. However, it neither recorded nor stratified patients by growth rate of disease prior to study entry. Since a proportion of newly diagnosed non-functioning carcinoid tumors can remain stable for years, it seems prudent to limit routine use of somatostatin analogs to those patients who have documented growth of their disease. Additionally, these data cannot be extrapolated for routine use in non-midgut tumors until confirmatory studies at these disease sites are performed.
Interferon as a single agent has also shown some apoptotic and cytostatic activity against GEP-NETs. However, the studies on IFN $\alpha$ in treatment of GEP-NETs have had small sample sizes and have not been randomized. IFN $\alpha$ leads to partial response in $11 \%$ of patients and disease stabilization in a median of $35 \%$, lasting 32 months. ${ }^{7,9}$

\section{Systemic chemotherapy}

Systemic chemotherapy for well-differentiated neuroendocrine tumors is relatively ineffective, with slightly higher response rates in pancreatic NETs than in carcinoid tumors. Poorly differentiated NETs, independent of their origin, behave much more aggressively but have better response rates to systemic chemotherapy, usually with a platinum-based regimen (eg, cisplatin and etoposide). This review, however, is limited to treatment of well differentiated NETs.

A variety of chemotherapy regimens have been tested for well-differentiated neuroendocrine tumors of the pancreas and include platinum analogs (cis or carbo), chlorozotocin, dacarbazine (and its oral analog temozolomide), doxorubicin, etoposide, streptozocin (STZ), and paclitaxel. Streptozocin was first studied as an antimicrobial agent and was subsequently seen to have antitumor activity and to cause hyperglycemia through degranulation of islet beta cells. These findings lead to the study of streptozocin in the treatment of pancreatic islet cell tumors in the late 1960s. Since that time, streptozocin has been studied in combination with other agents, most notably in the 1992 multicenter, randomized study by Moertel et al in which 105 patients with advanced islet cell carcinoma were randomized to receive one of three treatment regimens: STZ $+5 \mathrm{FU}, \mathrm{STZ}+$ doxorubicin, or chlorozotocin monotherapy. ${ }^{14} \mathrm{STZ}+$ doxorubicin was superior in terms of tumor regression, progression-free survival, and overall survival. Benefits were offset by toxicities of that regimen which included nausea and vomiting, myelosuppression, and anthracycline-induced cardiomyopathy (see Table 1).

Dacarbazine monotherapy has also been studied in the treatment of well-differentiated GEP-NETs. Studies have demonstrated overall response rates between $30 \%$ and $40 \%$, sustained for 3 to 24 months. ${ }^{15,16}$ The most common toxicities associated with this regimen were mild nausea and vomiting. Overall, dacarbazine is better tolerated and is easier to administer when compared with STZ combinations, although in non-randomized comparisons STZ combinations appear to be slightly more effective.

Temozolomide, an oral alternative to dacarbazine with a similar mechanism of action, has recently been studied in combination with thalidomide, a putative anti-angiogenesis agent. 
Table I Randomized clinical trials of chemotherapy in GEP-NETs

\begin{tabular}{|c|c|c|c|c|c|c|c|}
\hline Regimen & Study design & Tumor type & $\mathbf{n}$ & RR (\%) & $\begin{array}{l}\text { TTP } \\
\text { (mo) }\end{array}$ & $\begin{array}{l}\text { OS } \\
\text { (mo) }\end{array}$ & Reference \\
\hline $\begin{array}{l}\text { Strep/5FU vs Strep/ } \\
\text { Cytoxan }\end{array}$ & Phase III & $\begin{array}{l}\text { Mixed carcinoid } \\
\text { and pancreas }\end{array}$ & $\begin{array}{l}42 \\
47\end{array}$ & $\begin{array}{l}33 \\
26\end{array}$ & - & - & Moertel $^{46}$ \\
\hline $\begin{array}{l}\text { Strep/5FU } \\
\text { vs Doxorubicin }\end{array}$ & Phase III & Carcinoid only & $\begin{array}{l}104 \\
91\end{array}$ & $\begin{array}{l}23 * \\
20\end{array}$ & $\begin{array}{l}7.8 \\
6.5\end{array}$ & $\begin{array}{l}16 \\
12\end{array}$ & Engstrom ${ }^{47}$ \\
\hline $\begin{array}{l}\text { Strep/Dox vs } \\
\text { Strep/5FU vs } \\
\text { Chlorotozocin }\end{array}$ & Phase III & Pancreas only & $\begin{array}{l}36 \\
33 \\
33\end{array}$ & $\begin{array}{l}69 * \\
45 \\
30\end{array}$ & $\begin{array}{l}69 * \\
45 \\
30\end{array}$ & $\begin{array}{l}26.4^{*} \\
16.8 \\
16.8\end{array}$ & Moertel $^{14}$ \\
\hline $\begin{array}{l}\text { Strep/5FU vs Dox/ } \\
5 \mathrm{FU}\end{array}$ & Phase III & $\begin{array}{l}\text { Mixed carcinoid } \\
\text { and pancreas }\end{array}$ & $\begin{array}{l}88 \\
88\end{array}$ & $\begin{array}{l}16 \\
15.9\end{array}$ & $\begin{array}{l}5.3 \\
4.5\end{array}$ & $\begin{array}{l}24.3^{*} \\
15.7\end{array}$ & Sun ${ }^{48}$ \\
\hline
\end{tabular}

$* P \leq 0.05$.

Abbreviations: Dox, doxorubicin; 5FU, 5-fluorouracil; n, number; OS, overall survival; RR, response rate; strep, streptozocin;TTP, time to progression.

In that study of 29 patients with well-differentiated NETs, a $25 \%$ radiologic response rate and a $40 \%$ biochemical response rate was observed. ${ }^{17}$ One of 14 patients with carcinoid responded while 5 of 11 patients with pancreatic NETs had radiographic responses. This once again confirms the observation that well-differentiated neuroendocrine tumors of the stomach, small and large intestine (ie, carcinoid tumors) are generally less responsive to systemic chemotherapy. Because temozolomide cytotoxicity is mediated by DNA alkylation and the DNA repair enzyme, methylguanine methyl transferase (MGMT) is responsible for repair of such adducts, tumors deficient in MGMT might be more sensitive to temozolomide. In fact, when neuroendocrine tumors are assayed for MGMT activity, the clinical responses correlate with MGMT deficiency. Additionally, MGMT deficiency is more common in pancreatic neuroendocrine tumors than in carcinoid tumors. ${ }^{18}$

Other temozolomide combinations also appear promising. In preliminary data on pancreatic NETs, combination of temozolomide + capecitabine has had very encouraging response rates $(70 \%)$ suggesting that this combination warrants further evaluation. ${ }^{19,20}$

\section{Locoregional therapies}

Hepatic metastases commonly occur in patients with GEPNETs and adversely affect overall prognosis and quality of life. Since the effectiveness of somatostatin analogs wanes over time, therapies directed at locoregional control of hepatic disease may be necessary to decrease symptoms associated with hormone excess. Surgery for hepatic metastases should be considered whenever the metastases are considered resectable and when there is no evidence of extrahepatic disease. Thermal ablation or cryoablation may be considered as an adjunct to surgery or in settings where extrahepatic disease or comorbidities might favor a less aggressive intervention.
Hepatic metastases from GEP-NETs have a preferential arterial blood supply compared with normal liver parenchyma, thus offering a selective advantage to intra-arterial therapies. Selective catheterization of the hepatic artery and embolization of vessels perfusing the tumor(s) can result in clinically significant responses. Embolization has been performed using fragments of absorbable gelatin sponge or polyvinyl alcohol particles. The latter was investigated in a small group of 22 patients who received a median number of four embolizations, resulting in a partial radiographic response in $60 \%$ of treated patients, also associated with symptom improvement and decrease in hormone levels. ${ }^{21}$

Transcatheter arterial chemoembolization also utilizes the preferential arterial perfusion to deliver an emulsion of cytotoxic drug with normal saline and iodized oil. This is followed by embolization with gelatin sponge $2-3 \mathrm{~mm}$ particles or microspheres which are placed distally in the distribution of the hepatic artery until a decrease in blood flow is observed. ${ }^{22}$ Chemoembolization is a reasonable firstline treatment in patients with symptomatic or progressive liver metastases, especially in patients with no clinically significant extrahepatic disease and in those with systemic symptoms that are no longer responsive to somatostatin analogs. Transcatheter arterial chemoembolization has proven effective both in terms of symptom relief and tumor response rates. Symptom relief has been reported in 63\% to $100 \%$ of patients treated. Additionally, objective tumor response rates of $33 \%$ to $80 \%$ have been confirmed in many series, independent of GEP-NET tumor type..$^{23}$ However, no benefit in overall survival has even been demonstrated, and comparisons between trials are problematic because of differences in cytotoxic agents and chemoembolization intervals. Post-embolization side effects include nausea, vomiting, abdominal pain, fever, and elevated liver AST and ALT. Major complications are rare, but include renal 
failure, liver failure, and bleeding peptic ulcers (due to inadvertent perfusion through the gastroduodenal artery).

Ultrasound-guided percutaneous alcohol injection, used historically in the treatment of hepatocellular carcinoma, has also been studied as an ablative therapy for small liver metastases from GEP-NETs. Alcohol causes coagulative necrosis followed by fibrosis and thrombosis of small vessels. Studies evaluating percutaneous alcohol injection for GEP-NETs have lacked good design and adequate patient numbers. This technique has therefore been abandoned for other interventional ablative therapies.

Radiofrequency (RF) ablation and cryotherapy are other interventional techniques aimed at regional destruction of liver metastases either alone or in combination with surgery for limited disease. RF ablation works by converting RF waves into heat and is considered in patients with fewer than 5 lesions and lesions less than $35 \mathrm{~mm}$ in size. Berber et al evaluated laparoscopic RF ablation and reported symptomatic response rates of $80 \%$ to $95 \%$, radiographic response rates of $97 \%$, and response duration of 6 to 24 months. ${ }^{24}$ Hepatic cryotherapy involves serial freezing/thawing of liver tumors by means of an intraoperative cryoprobe which leads to tumor necrosis. This technique is frequently used at the time of surgery and has demonstrated successful results in terms of symptom control and tumor responses.

Radioembolization with selective internal radiation microspheres has been used for years to treat patients with unresectable liver metastases from primary and secondary liver cancers. A recent study specifically evaluated this treatment in patients with neuroendocrine liver metastases. Symptomatic responses were observed in 18 of $32(55 \%)$ at 3 months and 16 of $32(50 \%)$ at 6 months. Radiographic responses were observed in $50 \%$ of patients and included 6 complete responses and 11 partial responses. Median overall survival was 29.4 months. $^{25}$

\section{lonizing radiation}

Somatostatin receptor scintigraphy has been used for the past 20 years to identify patients with somatostatin-positive disease and otherwise undetectable metastatic foci. This same principle has been applied using radiolabeled somatostatin analogs with therapeutic doses of the radioactive isotope. The most commonly used radionuclides are indium $\left({ }^{111} \mathrm{I}\right)$, yttrium $\left({ }^{90} \mathrm{Y}\right)$, and lutetium $\left({ }^{177} \mathrm{Lu}\right)$ and are only available in Europe. A study in patients with GEP-NETs demonstrated clinical responses in $46 \%$ of patients at three months (complete $2 \%$, partial $28 \%$, and minor $16 \%$ ) and stable disease in $36 \%$; the minority had progressive disease $(20 \%)$. Median time to progression was 40 months and median overall survival was 128 months. The bone marrow and kidneys are the most important dose-limiting organs in peptide receptor radionuclide therapy. ${ }^{26}$

\section{External beam radiation}

External beam radiation therapy is of limited value in gastroenteropancreatic NETs and its main use is in palliative

Table 2 Selected clinical trials using targeted agents in GEP-NETs

\begin{tabular}{|c|c|c|c|c|c|c|c|}
\hline Regimen & Study design & Tumor type & $\mathbf{n}$ & $\mathbf{R R}(\%)$ & $\begin{array}{l}\text { PFS or } \\
\text { TTP } \\
\text { (mo) }\end{array}$ & $\begin{array}{l}\text { One year } \\
\text { survival (\%) }\end{array}$ & Reference \\
\hline \multicolumn{8}{|c|}{ Angiogenesis inhibitors } \\
\hline $\begin{array}{l}\text { Temozolamide }+ \\
\text { thalidomide }\end{array}$ & $\begin{array}{l}\text { Phase II, } \\
\text { single arm }\end{array}$ & $\begin{array}{l}\text { Mixed carcinoid, } \\
\text { pancreas and } \\
\text { pheochromocytoma }\end{array}$ & 29 & $\begin{array}{l}45(p) \\
7(c)\end{array}$ & 13.5 & 79 & Kulke $^{17}$ \\
\hline 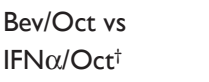 & $\begin{array}{l}\text { Phase II, } \\
\text { randomized }\end{array}$ & Carcinoid only & $\begin{array}{l}22 \\
22\end{array}$ & $\begin{array}{l}18 \\
0\end{array}$ & - & 93 & $\mathrm{Yao}^{27}$ \\
\hline \multicolumn{8}{|c|}{ Tyrosine kinase inhibitors } \\
\hline Sunitinib & $\begin{array}{l}\text { Phase II, } \\
\text { Single arm }\end{array}$ & $\begin{array}{l}\text { Mixed carcinoid and } \\
\text { pancreas }\end{array}$ & 109 & $\begin{array}{l}17(p) \\
2(c)\end{array}$ & $\begin{array}{l}7.7(p) \\
10.2(c)\end{array}$ & $\begin{array}{l}81 \\
83\end{array}$ & Kulke $^{32}$ \\
\hline $\begin{array}{l}\text { Sunitinib vs } \\
\text { placebo }\end{array}$ & $\begin{array}{l}\text { Phase III, } \\
\text { randomized }\end{array}$ & Pancreatic only & $\begin{array}{l}75 \\
79\end{array}$ & - & $\begin{array}{l}\text { II.I } \\
5.5\end{array}$ & - & Raymond ${ }^{33}$ \\
\hline mTOR inhibitor & & & & & & & \\
\hline $\begin{array}{l}\text { RAD00I vs } \\
\text { RAD00I+ Oct }\end{array}$ & $\begin{array}{l}\text { Phase II, } \\
\text { two arm }\end{array}$ & Pancreatic only & $\begin{array}{l}115 \\
45\end{array}$ & $\begin{array}{l}7.8 \% \\
4.4 \%\end{array}$ & $\begin{array}{l}9.3 \\
12.9\end{array}$ & $\begin{array}{l}50 \\
90\end{array}$ & $Y^{41}$ \\
\hline
\end{tabular}

Abbreviations: Bev, bevacizumab; IFN $\alpha$, interferon alpha; Oct, octreotide; C, carcinoid; P, pancreas; PFS, progression-free survival; RR, response rate; TTP, time to progression. Note: ${ }^{\dagger}$ crossover allowed at 18 weeks. 


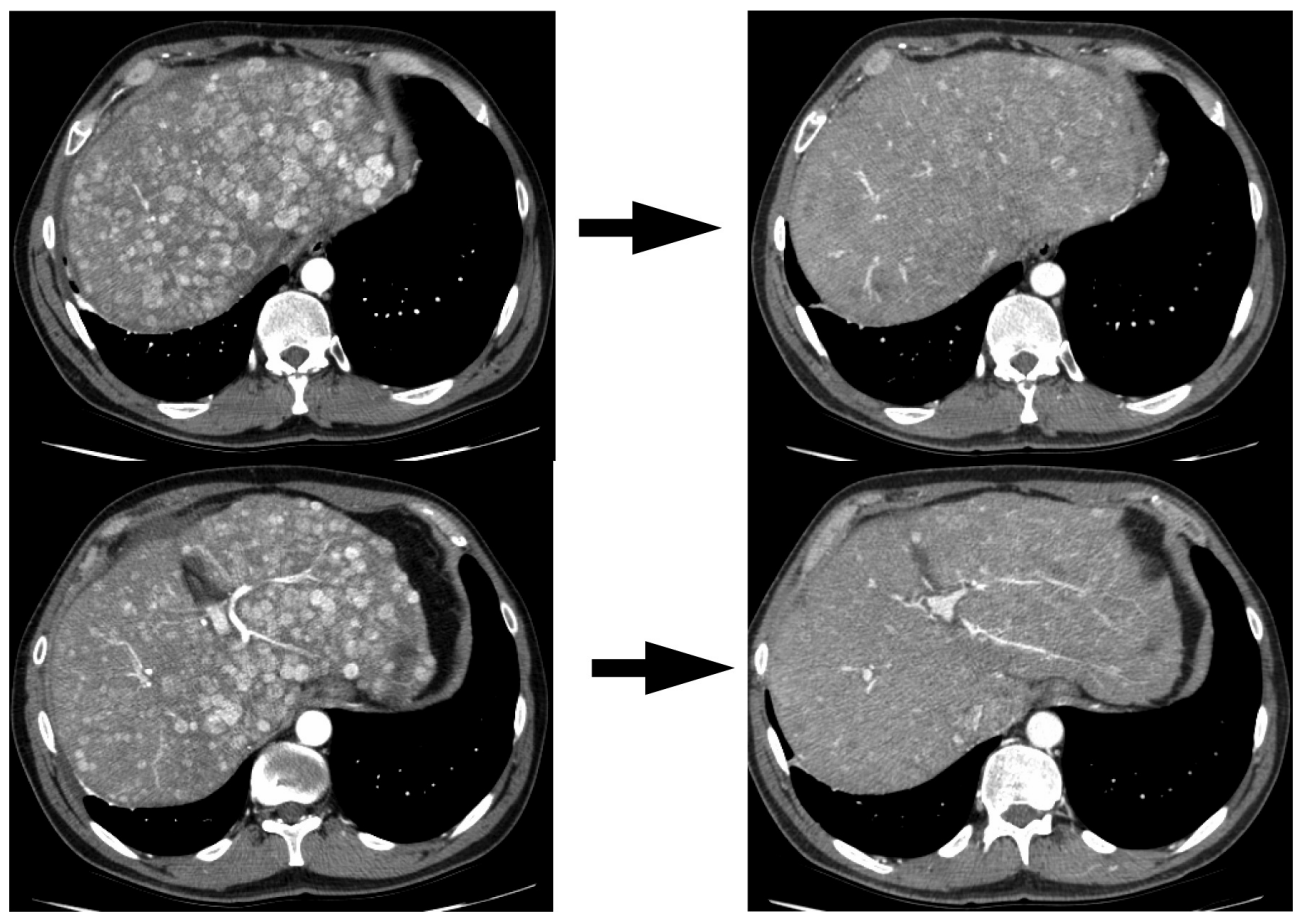

Figure I Response to bevacizumab, capecitabine, and oxaliplatin.

On left are two cuts demonstrating the characteristic appearance of enhancing liver lesions (note that aorta is bright white signifying arterial phase scan) in a patient with a pancreatic neuroendocrine tumor. On right are corresponding cuts after 2 cycles ( 6 weeks) of bevacizumab, capecitabine, and oxaliplatin demonstrating marked decrease in vascularity of lesions.

therapy of the rare bone and brain metastases associated with this disease. Response rates of larger masses are low and anecdotal. Although efficacy data are lacking, its use may be reasonable in settings where resection of primary disease leaves positive margins such as in pancreatic or rectal neuroendocrine primaries. Stereotactic radiosurgery is being explored as an ablative technique for limited liver lesions on an experimental basis at our institution.

\section{Targeted agents in clinical trials Angiogenesis inhibitors}

A trial of temozolomide and thalidomide, a putative first generation angiogenesis inhibitor, was discussed in the systemic chemotherapy section above. ${ }^{17}$ Bevacizumab, a monoclonal antibody that binds to vasculoendothelial growth factor (VEGF-A), is a more potent angiogenesis inhibitor and has demonstrated some encouraging early data in carcinoid tumors (see Table 2). In a study of 44 patients on octreotide and randomly assigned to either interferon or bevacizumab, a significant prolongation in progression-free survival was noted, favoring the bevacizumab arm (95\% versus 68\%). ${ }^{27}$ This study was then designed to allow all patients to receive all three drugs (octreotide, bevacizumab, and interferon) after 18 weeks on study. This triplet biologic therapy resulted in a biochemical response rate of $46 \%$ with the majority of radiographic tumor responses occurring in the arm in which bevacizumab was administered first. Median progression-free survival by initial treatment assignment was not significant. Another study evaluating temozolomide and bevacizumab for advanced NETs showed a partial response rate of $14 \%$, stable disease in $79 \%$, with biochemical response in 36\% (decrease in chromogranin A). ${ }^{28}$ Other trials utilizing bevacizumab, oxaliplatin, and a fluoropyrimidine are ongoing and have shown promising preliminary results. ${ }^{29,30}$

Data demonstrating marked reduction in perfusion of tumors after administration of angiogenesis inhibitors (see Figure 1) may provide a valuable surrogate marker of response in a disease for which radiographic responses are rare and the slow growth rate of most of these tumors makes assessment of progression-free survival problematic. ${ }^{31}$

\section{Tyrosine kinase inhibitors}

Oral multitargeted tyrosine kinase inhibitors (TKI) are being studied as monotherapies. In a phase II single-arm study, sunitinib (50 mg/day, 4 weeks on, 2 weeks off) showed an overall response rate of $17 \%$ in patients with pancreatic NETs and $2.4 \%$ in patients with carcinoid tumors. Median time to progression was 7.7 months versus 10.2 months in pancreatic NET and carcinoid tumor patients, respectively. The treatment was tolerated well with minimal side effects. ${ }^{32}$ 
A recent phase III trial of sunitinib in patients with metastatic pancreatic NETs was conducted in Europe. Patients were randomized to receive either sunitinib $(37.5 \mathrm{mg}$ /day continuous daily dosing) or placebo. Progression-free survival increased from 5.5 months in the placebo group to 11.1 months in the sunitinib group $(P<0.001)$. The study was discontinued prematurely by a data safety monitoring committee because of benefit observed in the sunitinib arm. Patients in the placebo arm were allowed to cross over. ${ }^{33}$

Sorafenib, a TKI primarily of VEGFR2 and PDGFR- $\beta$, has shown some modest activity in metastatic GEP-NETs. In a Phase II study by Hobday, ${ }^{34}$ the combined partial response + minor response rate was $17 \%$ for carcinoid tumor patients and $32 \%$ for pancreatic NET patients. Six-month progression-free survival was higher in the pancreatic group. Grade 3-4 toxicity occurred in $43 \%$ of patients. Phase III trial of sorafenib versus placebo is underway.

Other TKIs have been evaluated, including vatalanib, a small molecule inhibitor primarily of VEGFR 2 and PDGFR- $\beta$, which has shown some antiproliferative activity. ${ }^{35,36}$ Gefitinib, a small molecule inhibitor of the EGFR tyrosine kinase, has also been studied and showed good tolerability and prolonged disease stabilization in patients with progressive metastatic NETs. ${ }^{37}$ However, imatinib, a TKI of ABL, PDGFR and c-kit, was studied in a small Phase II study and showed significant toxicity without meaningful clinical activity. ${ }^{38}$

\section{Other biologic agents}

Another promising class of agents is the inhibitors of mTOR (mammalian targets of rapamycin). Temsirolimus has demonstrated single agent activity and, more recently, everolimus has shown promising activity in combination with octreotide. ${ }^{39-41}$ Phase III studies with everolimus are ongoing.

Other novel agents evaluated in recent clinical trials include bortezomib (a proteasome inhibitor), ${ }^{42}$ atiprimod (a novel proapoptotic and antiangiogenic drug), ${ }^{43}$ AMG 479 (fully human monoclonal $\mathrm{Ab}$ antagonist of IGF-1R), ${ }^{44}$ and lithium carbonate (an inhibitor of glycogen synthase kinase-3 $\beta$ ). ${ }^{45}$

\section{Conclusion}

Gastroenteropancreatic neuroendocrine tumors are biologically diverse, characteristically hypervascular, and clinically quite often indolent in growth rate. The rarity of these tumors, their resistance to standard chemotherapy, and the excellent performance status of most of these patients, make a strong argument for consideration of novel therapeutic trials at tertiary care centers that specialize in this disease. Better understanding of the biology of the disease and application of newly available less toxic drug combinations is reasonable cause for optimism in offering these patients longer quality-filled life expectancies.

\section{Disclosure}

The authors report no conflicts of interest in this work.

\section{References}

1. Yao JC, Hassan M, Phan A, et al. One hundred years after "carcinoid": Epidemiology of and prognostic factors for neuroendocrine tumors in 35,825 cases in the United States. J Clin Oncol. 2008;26(18):3063-3072.

2. Solcia E, Klöppel G, Sobin LH, Williams ED, World Health Organization. Histological typing of endocrine tumours. 2nd ed. Berlin; New York: Springer, 2000.

3. Thulin L, Samnegard H, Tyden G, Long DH, Efendic S. Efficacy of somatostatin in a patient with carcinoid syndrome. Lancet. 1978;2(8079):43.

4. Guillemin R. Peptides in the brain: The new endocrinology of the neuron. Science (New York, NY) 1978;202(4366):390-402.

5. Eriksson B, Oberg K. Summing up 15 years of somatostatin analog therapy in neuroendocrine tumors: Future outlook. Ann Oncol. 1999;10 Suppl 2:S31-S38.

6. Rubin J, Ajani J, Schirmer W, et al. Octreotide acetate long-acting formulation versus open-label subcutaneous octreotide acetate in malignant carcinoid syndrome. J Clin Oncol. 1999;17(2):600-606.

7. Shah T, Caplin M. Endocrine tumours of the gastrointestinal tract. Biotherapy for metastatic endocrine tumours. Best Pract Res Clin Gastroenterol. 2005;19(4):617-636.

8. O'Toole D, Ducreux M, Bommelaer G, et al. Treatment of carcinoid syndrome: A prospective crossover evaluation of lanreotide versus octreotide in terms of efficacy, patient acceptability, and tolerance. Cancer. 2000;88(4):770-776.

9. Oberg K, Eriksson B. The role of interferons in the management of carcinoid tumours. Br J Haematol. 1991;79 Suppl 1:74-77.

10. Faiss S, Pape UF, Bohmig M, et al. Prospective, randomized, multicenter trial on the antiproliferative effect of lanreotide, interferon alfa, and their combination for therapy of metastatic neuroendocrine gastroenteropancreatic tumors - the International Lanreotide and Interferon Alfa Study Group. J Clin Oncol. 2003;21(14):2689-2696.

11. Arnold R, Trautmann ME, Creutzfeldt W, et al. Somatostatin analogue octreotide and inhibition of tumour growth in metastatic endocrine gastroenteropancreatic tumours. Gut. 1996;38(3):430-438.

12. Saltz L, Trochanowski B, Buckley M, et al. Octreotide as an antineoplastic agent in the treatment of functional and nonfunctional neuroendocrine tumors. Cancer. 1993;72(1):244-248.

13. Rinke A, Muller HH, Schade-Brittinger C, et al. Placebo-controlled, double-blind, prospective, randomized study on the effect of octreotide LAR in the control of tumor growth in patients with metastatic neuroendocrine midgut tumors: A report from the PROMID Study Group. J Clin Oncol. 2009;27(28):4656-4663.

14. Moertel CG, Lefkopoulo M, Lipsitz S, Hahn RG, Klaassen D. Streptozocin-doxorubicin, streptozocin-fluorouracil or chlorozotocin in the treatment of advanced islet-cell carcinoma. $N$ Engl $J$ Med. 1992;326(8):519-523.

15. Arnold R, Rinke A, Schmidt C, Hofbauer L. Endocrine tumours of the gastrointestinal tract: Chemotherapy. Best Pract Res Clin Gastroenterol. 2005;19(4):649-656.

16. Ramanathan RK, Cnaan A, Hahn RG, Carbone PP, Haller DG. Phase II trial of dacarbazine (DTIC) in advanced pancreatic islet cell carcinoma. Study of the Eastern Cooperative Oncology Group-E6282. Ann Oncol. 2001;12(8):1139-1143.

17. Kulke MH, Stuart K, Enzinger PC, et al. Phase II study of temozolomide and thalidomide in patients with metastatic neuroendocrine tumors. J Clin Oncol. 2006;24(3):401-406. 
18. Kulke MH, Hornick JL, Frauenhoffer $\mathrm{C}$, et al. $\mathrm{O}_{6}$-methylguanine DNA methyltransferase deficiency and response to temozolomide-based therapy in patients with neuroendocrine tumors. Clin Cancer Res. 2009;15(1):338-345.

19. Isacoff W, Moss R, Pecora A, Fine R. Temozolomode/capecitabine therapy for metastatic neuroendocrine tumors of the pancreas. A retrospective review. J Clin Oncol. 2006;24(June 20 Suppl): Abstr 14023.

20. Strosberg J, Choi J, Gardner N, Kvols L. First-line treatment of metastatic pancreatic endocrine carcinomas with capecitabine and temozolomide. J Clin Oncol. 2008;26(May 20 Suppl): Abstr 4612.

21. Ajani JA, Carrasco CH, Charnsangavej C, Samaan NA, Levin B, Wallace S. Islet cell tumors metastatic to the liver: Effective palliation by sequential hepatic artery embolization. Ann Intern Med. 1988;108(3):340-344.

22. Therasse E, Breittmayer F, Roche A, et al. Transcatheter chemoembolization of progressive carcinoid liver metastasis. Radiology. 1993;189(2):541-547.

23. O'Toole D, Ruszniewski P. Chemoembolization and other ablative therapies for liver metastases of gastrointestinal endocrine tumours. Best Pract Res Clin Gastroenterol. 2005;19(4):585-594.

24. Berber E, Flesher N, Siperstein AE. Laparoscopic radiofrequency ablation of neuroendocrine liver metastases. World J Surg. 2002;26(8):985-990.

25. King J, Quinn R, Glenn DM, et al Radioembolization with selective internal radiation microspheres for neuroendocrine liver metastases. Cancer. 2008;113(5):921-929.

26. Kwekkeboom DJ, de Herder WW, Kam BL, et al.Treatment with the radiolabeled somatostatin analog [177 Lu-DOTA 0,Tyr3] octreotate: Toxicity, efficacy, and survival. J Clin Oncol. 2008;26(13): 2124-2130

27. Yao JC, Phan A, Hoff PM, et al. Targeting vascular endothelial growth factor in advanced carcinoid tumor: A random assignment phase II study of depot octreotide with bevacizumab and pegylated interferon alpha-2b. J Clin Oncol. 2008;26(8):1316-1323.

28. Kulke M, Stuart K, Earle C, et al. A phase II study of temozolomide and bevacizumab in patients with advanced neuroendocrine tumors. J Clin Oncol. 2006;24(June 20 Suppl): Abstr 4044.

29. Kunz P, Kuo T, Kaiser H, et al. A phase II study of capecitabine, oxaliplatin, and bevacizumab for metastatic or unresectable neuroendocrine tumors: Preliminary results. J Clin Oncol. 1008;26(May 20 Suppl): Abstr 15502.

30. Venook A, Ko A, Tempero M, et al. Phase II trial of FOLFOX plus bevacizumab in advanced, progressive neuroendocrine tumors. $J$ Clin Oncol. 1008;26(May 20 Suppl): Abstr 15545.

31. Yao JC, Ng C, Hoff PM, et al. Improved progression free survival (PFS), and rapid, sustained decrease in tumor perfusion among patients with advanced carcinoid treated with bevacizumab. 2005 ASCO Annual Meeting Proceedings J Clin Oncol. 2005;23(June 1 Suppl, Part 1): Abstr 4007.

32. Kulke MH, Lenz HJ, Meropol NJ, et al. Activity of sunitinib in patients with advanced neuroendocrine tumors. J Clin Oncol. 2008;26(20): 3403-3410.

33. Raymond E, Raoul J, Niccoli P. Phase III, randomized, double-blind trial of sunitinib versus placebo in patients with progressive, welldifferentiated pancreatic islet cell tumours. 11th World Congress on Gastrointestinal Cancer (ESMO 2009), Barcelona, Spain: 2009 June 30-July 03. Abstr 0013.

Clinical and Experimental Gastroenterology

\section{Publish your work in this journal}

Clinical and Experimental Gastroenterology is an international, peerreviewed, open access journal, publishing all aspects of gastroenterology in the clinic and laboratory, including: Pathology, pathophysiology of gastrointestinal disease; Investigation and treatment of gastointestinal disease; Pharmacology of drugs used in the alimentary tract;
34. Hobday T, Rubin J, Holen K, et al. MC044h, a phase II trial of sorafenib in patients (pts) with metastatic neuroendocrine tumors (NET): A Phase II Consortium (P2C) study. ASCO Annual Meeting Proceedings. J Clin Oncol. 2007;25(June 20 Suppl):Abstr 4504.

35. Pavel M, Bartel C, Heuck F, et al. Open-label, non-randomized, multicenter phase II study evaluating the angiogenesis inhibitor PTK787/ ZK222584 (PTK/ZK) in patients with advanced neuroendocrine carcinomas (NEC). J Clin Oncol. 2008;26(May 20 Suppl): Abstr 14684.

36. Anthony L, Chester M, Michael S, O'Dorisio T, O'Dorisio M. Phase II open-label clinical trial of vatalanib (PTK/ZK) in patients with progressive neuroendocrine cancer. J Clin Oncol. 2008;26(May 20 Suppl): Abstr 14624.

37. Hobday T, Holen K, Donehower R, et al. A phase II trial of gefitinib in patients (pts) with progressive metastatic neuroendocrine tumors (NET): A Phase II Consortium (P2C) study. ASCO Annual Meeting Proceedings J Clin Oncol. 2006;24(June 20 Suppl Part 1): Abstr 4043.

38. Gross DJ, Munter G, Bitan M, et al. The role of imatinib mesylate (Glivec) for treatment of patients with malignant endocrine tumors positive for c-kit or PDGF-R. Endocr Relat Cancer. 2006;13(2):535-540.

39. Duran I, Kortmansky J, Singh D, et al. A phase II clinical and pharmacodynamic study of temsirolimus in advanced neuroendocrine carcinomas. Br J Cancer. 2006;95(9):1148-1154.

40. Yao JC, Phan AT, Chang DZ, et al Efficacy of RAD001 (everolimus) and octreotide LAR in advanced low- to intermediate-grade neuroendocrine tumors: results of a phase II study. J Clin Oncol. 2008;26(26): 4311-4318.

41. Yao J, Lombard-Bohas C, Baudin E, et al. A phase II trial of daily oral RAD001 (everolimus) in patients with metastatic pancreatic neuroendocrine tumors (NET) after failure of cytotoxic chemotherapy. 2009 Gastrointestinal Cancers Symposium. Abstr 122.

42. Shah M, Martin E, Ellison C, et al. A phase II study of proteasome inhibitor PS-341 in metastatic neuroendocrine tumors. Proc Am Soc Clin Oncol. 2002;21: Abstr 111.

43. Sung M, Kvols L, Wolin E, et al. Phase II proof-of-concept study of atiprimod in patients with advanced low- to intermediate-grade neuroendocrine carcinoma. J Clin Oncol 2008;26(May 20 Suppl):Abstr 4611.

44. Rothenberg M, Tolcher A, Sarantopoulos J, et al. AMG 479 monotherapy to treat patients with advanced GI carcinoid tumors: A subset analysis from the first-in-human study. 2009 Gastrointestinal Cancers Symposium. Abstr 386.

45. Lubner S, Chen H, Holen K, et al. A phase II clinical and biological study of lithium carbonate ( $\mathrm{Li}$ ) in patients with low-grade neuroendocrine tumors. J Clin Oncol. 2009;27 Suppl: Abstr e15662.

46. Moertel CG, Hanley JA. Combination chemotherapy trials in metastatic carcinoid tumor and the malignant carcinoid syndrome. Cancer Clin Trials. 1979;2(4):327-334.

47. Engstrom PF, Lavin PT, Moertel CG, Folsch E, Douglass HO Jr. Streptozocin plus fluorouracil versus doxorubicin therapy for metastatic carcinoid tumor. J Clin Oncol. 1984;2(11):1255-1259.

48. Sun W, Lipsitz S, Catalano P, Mailliard JA, Haller DG. Phase II/III study of doxorubicin with fluorouracil compared with streptozocin with fluorouracil or dacarbazine in the treatment of advanced carcinoid tumors: Eastern Cooperative Oncology Group Study E1281. J Clin Oncol. 2005;23(22):4897-4904.

\footnotetext{
Submit your manuscript here: http://www.dovepress.com/clinical-and-experimental-gastroenterology-journal
}

\section{Dovepress}

Immunology/genetics/genomics related to gastrointestinal disease. This journal is indexed on CAS. The manuscript management system is completely online and includes a very quick and fair peer-review system. Visit http://www.dovepress.com/testimonials.php to read real quotes from published authors. 